\title{
STATISTICAL SURVEY ON INSPECTION, DIAGNOSIS AND REPAIR OF WALL RENDERINGS
}

\author{
Gonçalo SÁ, João SÁ, Jorge DE BRITO, Bárbara AMARO \\ IST - Technical University of Lisbon, Av. Rovisco Pais, 1049-001 Lisbon, Portugal
}

Received 06 Sep 2012; accepted 19 Dec 2012

\begin{abstract}
This paper describes a statistical survey on the pathology, diagnosis and rehabilitation of wall renderings. The survey was based on an inspection and diagnosis support system that comprises the classification of anomalies in renderings, their most probable causes, diagnosis methods and repair and maintenance techniques. The on-site work that led to this statistics collection involved standard inspections of 55 buildings, located in Lisbon, and a total of 150 wall renderings (100 external and 50 interior). The results of this survey provide indications on the intervention actions at the design, execution and use/maintenance stages in order to decrease the magnitude of or eradicate anomalies in wall renderings. The implementation of a system of this kind could directly improve the quality of constructions.
\end{abstract}

Keywords: inspection and diagnosis system, rendering, anomalies, causes, pathology, diagnosis, rehabilitation, statistical survey.

\section{Introduction}

Since Antiquity renderings have had an important role in the protection, levelling and finishing of masonry. This type of coating is characterised by its essentially inorganic nature and its performance is a function of the characteristics of its components, the nature and state of the substrates, the surrounding environmental conditions and the preparation and application procedures. To properly perform its functions a rendering must comply with the following functional demands: aesthetics, water vapour permeability, workability and consistency, water retention, adherence to and compatibility with the substrate, durability and mechanical/shock and cracking resistance. Furthermore, the state of renderings has a great influence on building performance, since they protect walls, user comfort regarding energy efficiency, and the aesthetics of built heritage, i.e. on people's welfare.

Old and recent buildings are generally told apart with 1945 as the threshold, when the frequency of use of cementitious materials dramatically increased. Recently, various authors have dedicated their work to the rehabilitation of renderings, both in old and recent buildings. A constant feature is the importance of the materials compatibility, in terms of cohesion with the original material and in terms of stability and maintenance of the properties over time (Schueremans et al. 2011; Pavlíková et al. 2011; Pacheco-Torgal et al. 2012).

The type of renderings under study in this paper is called "current", i.e. it contains cement, which is accordance with the usual recent buildings (after 1945). This type of material has been the subject of recent studies, namely focused on the evaluation of its durability (Norvaišiene et al. 2004) and in-service performance (Gaspa, de Brito, 2011; Hernández-Olivaresa, MayorLobo 2011; Flores-Colen et al. 2009). However there is a shortcoming concerning the inspection and repair of these renderings, which is the subjectivity inherent to diagnosis and decision-making that depends on the level of expertise of the inspector.

Therefore, an inspection and diagnosis system for wall renderings was developed by the authors, in order to simplify the inspection procedures and facilitate decisionmaking. This system is based both on extensive literature and fieldwork and is presented elsewhere (Sá et al. 2014).

In this paper a statistical analysis of wall rendering pathology is presented, is based on the data collected while performing the validation of the referred system.

\section{Inspection and diagnosis system}

The mentioned expert-based inspection and diagnosis system intends to aid inspectors by providing information that allows the identification of anomalies/defects in wall rendering by visual appraisal. This particular criterion is used so that anomalies which produce identical or similar visual effects can be treated as the same anomaly. Further on, it provides correlations between the anomalies and their most probable causes, auxiliary diagnosis tests and adequate repair techniques.

Corresponding author: Jorge De Brito

E-mail: jb@civil.ist.utl.pt 
To that purpose, available information was collected from national and international literature on anomalies, causes and diagnosis of wall renderings, such as FloresColen et al. (2008, 2009, 2011), Binda et al. (2010), Freire et al. (2006), Gaspar and de Brito (2005), Araújo (2002), Vallens et al. (2001), and Veiga (2000), as well as literature on repair techniques used in this type of coating (Flores-Colen et al. 2008; Silva 2004; Candel et al. 1997).

The research allowed building a classification list of 14 types of anomalies, divided in 3 groups: aesthetic, associated with damp and anomalies of mechanical origin. Classification lists for the remaining variables (causes, diagnosis techniques and repair techniques) were also developed, concerning the pathology of wall renderings. The acronyms are presented in the "acronym list" and the terms used are mostly self-explanatory.

After compiling the knowledge and sorting it in order to systemize the inspection procedures, they were implemented on field in a representative sample of 150 wall renderings.

The fieldwork allows adjusting and validating the literature-based inspection and diagnosis system and the collected data enables a statistical survey, as presented in this paper.

This type of approach is coherent with other similar works based on research by the same research team, developed over the last few years (Silvestre, de Brito 2011; Garcez et al. 2012; Palha et al. 2012; Pereira et al. 2014, among others). However, it is hereby presented, for the first time, a study applied to the domain of wall renderings, which denotes the innovation and usefulness of this paper.

\section{Characterisation of the sample}

The sample used to collect data consists of 150 wall renderings (100 external and 50 interior) from 55 buildings located in Lisbon metropolitan area, in Portugal. Since there are many parameters that may influence the durability of a render, buildings were chosen considering different ages and exposure conditions, in order to cover various case scenarios and define reliable correlations.

\subsection{Characterisation of the wall renders}

It was established beforehand that the sample would contain $2 / 3$ of external rendered surfaces (façades) and $1 / 3$ of interior ones (rooms). External renderings were organised by façade type and orientation. Interior renderings were classified by room type (Fig. 1) and orientation of the surfaces where the anomalies occur.

The sample is also characterised by a ratio of $87 \%$ current renders (here understood as prepared and proportioned on site using traditional techniques) to $13 \%$ single-layer (pre-mixed) renders. It was assumed that renders prior to the early 1990s were traditional (true for the Portuguese market). Furthermore, a market survey was carried out to estimate the 1990s-on representativeness of single-layer render versus current renders. The following 1990-2000 reference data were obtained: external pre-mixed renders represented $4-6 \%$ and interior ones $18-20 \%$. The pre-mixed market significantly expanded in the period 2000-2010 and the previous figures became $9-11 \%$ and $57-65 \%$ respectively.

\subsection{Age of the buildings}

As referred, the object of this study are cementitious renderings which are common in the so called "recent buildings" built after 1945 .

The sample includes buildings dated from 1955 up to 2009, as shown in Figure 2, taking the construction date as reference, or the last rehabilitation date for those examples in which the intervention on the rendering was integral and deep, thus allowing the age of the renderings inspected to be characterised.

\section{Fieldwork procedure}

In order to gather organized data during the fieldwork, an inspection plan was developed which includes filling inspection and validation files. In these files, each inspected element was characterized, its pathological phenomena registered, possible causes studied and tests to confirm the diagnosis recommended, according to the specific conditions of each case.

For the purpose of collecting statistical data and validating the system, the inspection plan was based

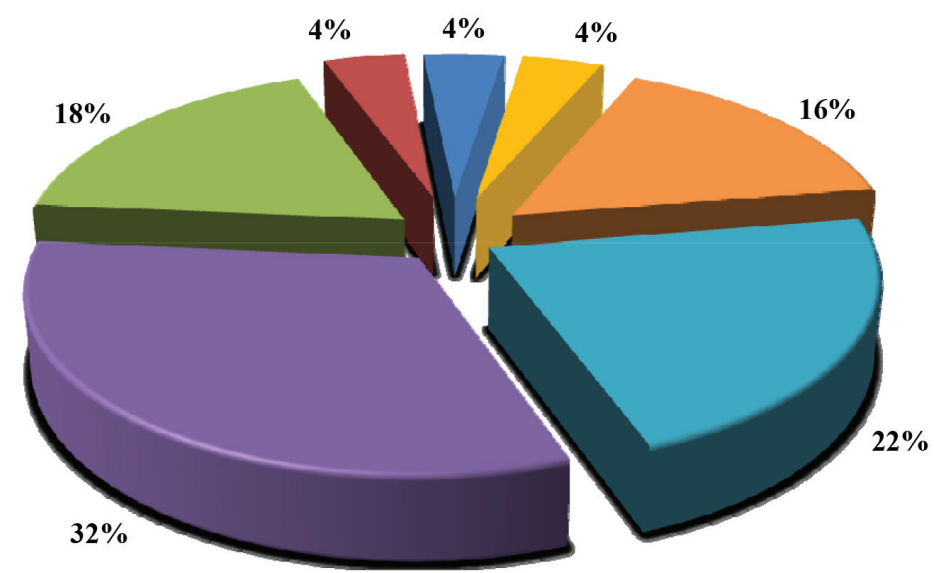

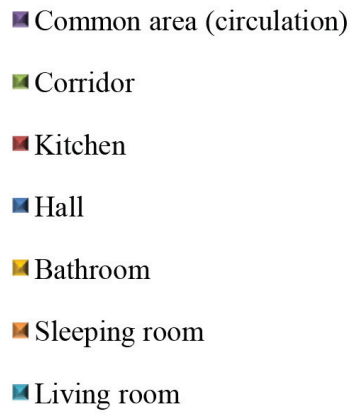

Fig. 1. Characterisation of the sample by type of interior rooms 


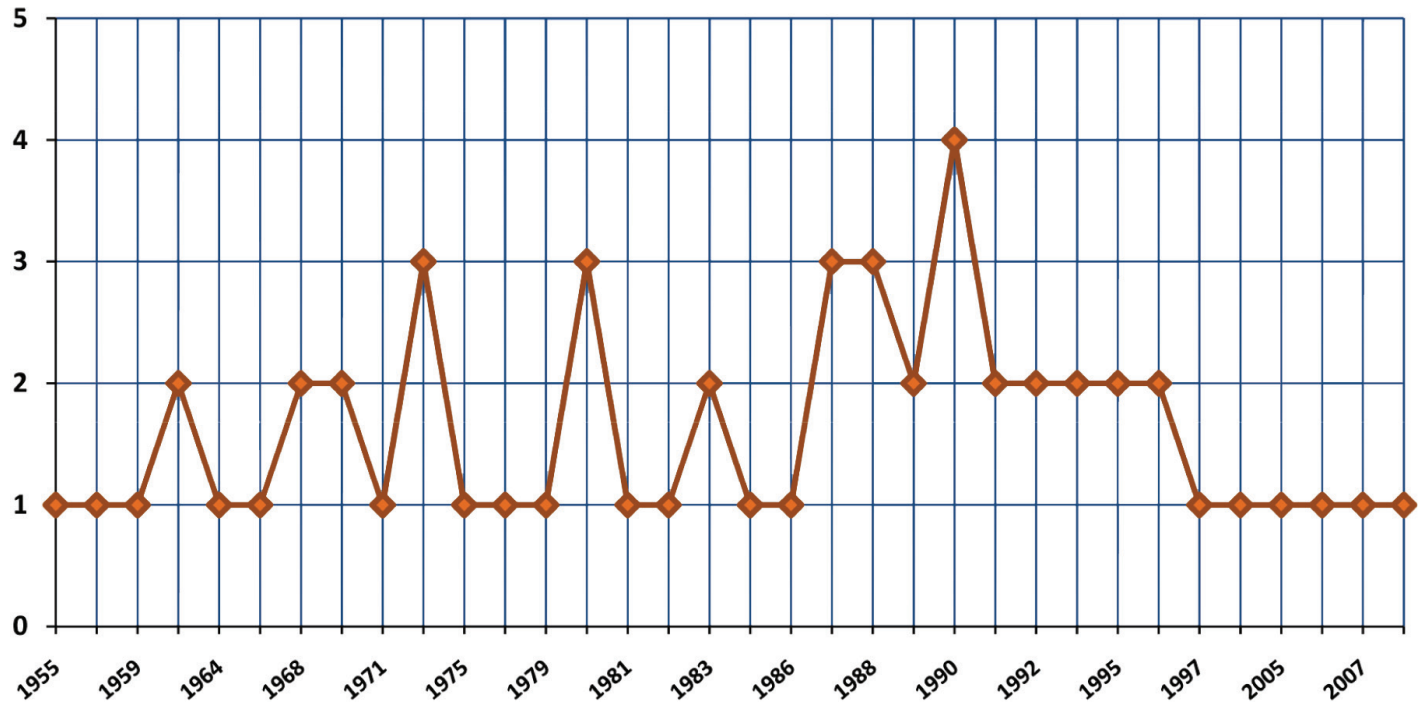

Fig. 2. Construction date of each building inspected (total of 55 buildings)

exclusively on visual inspection, since of the goal of the mentioned "inspection and diagnosis system" is to allow the identification and classification of each anomaly visually.

Mapping the anomalies is also fundamental for the rehabilitation process because it avoids the need to re-inspect the rendered surfaces before repair and for the monitoring process and post-intervention inspections because it enables the results of the rehabilitation to be appraised.

Due to time and money constraints no in situ or laboratory tests or repair/maintenance techniques were actually performed. The probable causes were listed as a result of reasoning according to the conditions surrounding the anomaly. In accessible areas, senses such as touch, smell and hearing (identification of different percussion sounds) also helped characterize the anomalies and indentify parameters such as humidity or loss of adherence.

Based on the findings (or their absence), additional testing was recommended (in situ tests) according to the data needed to complete a diagnosis.

Repair techniques were suggested, considering the repair of the anomalies and the fixing of their probable causes. The decision also depends on the gravity or urgency of the situation.

\subsection{Inspection files}

Inspection files characterise the building in general and the wall renderings in particular. Every detail that may be of relevance to the diagnosis is inscribed on inspection files, such as type of location, materials, type of texture, environmental conditions, orientation, colours and constructive features, among others. They synthesise and structure the data collected during inspections, and therefore they give a valuable contribution to the correct determination of the causes/origins of the anomalies, and prescribe the rehabilitation techniques. The standard inspection file developed was built iteratively by a process of theoretical construction/simulation of real situations.

The data needed to complete the files are not always available, especially if the builder/owner/manager of the building under analysis cannot be contacted in advance. Data collection is harder in relatively old buildings where technical documents on previous maintenance interventions, if any, are scarce and rarely available.

\subsection{Validation files}

Validation files were developed to supplement inspection files with the goal of registering the anomalies detected and validating the proposed system tools. The anomalies found, their characterization, probable causes, auxiliary testing and repair techniques are registered in these files. They were completed for each of the rooms/façades inspected. Comparing on site data with the system's literature-based data validated the latter.

\section{Statistical analysis}

With the data collected from the inspections, besides validating the inspection and diagnosis proposed system, a statistical analysis was made, providing additional information about the pathology of wall renderings.

In the 150 rendered surfaces inspected, 476 anomalies were identified (visually) and associated with 1277 causes (887 direct and 390 indirect), which means it takes an average of 2.7 causes to originate an anomaly. Also, 908 diagnosis methods were found to be suitable to analyse the anomalies, amounting to an average of 1.9 methods per anomaly.

Finally, 1731 repair/maintenance techniques were identified as valid alternatives to cope with the anomalies detected and their causes, i.e. 3.6 techniques per anomaly. At first instance, this value may seem high but the repair methods do not apply only to the correction of the anomaly, since they may also be recommended to eliminate its 
causes. Therefore, considering one anomaly plus its 2.7 causes, a total of 3.6 repair techniques may be seen as a reasonable number. Another reason may be the fact that some repair techniques are alternative to each other.

\subsection{Anomalies}

As referred, 476 anomalies were identified on the sample. Even though all anomalies are important when inspecting a wall rendering, in order to maintain or improve its performance, some may be considered more serious, depending on how much they affect the render. Therefore, besides studying the frequency of each phenomenon, other variables were taken into account, such as the level of urgency, the orientation of the façades, its exposure and its age.

Figure 3 graphically compiles the inspection data on anomalies and provides an overview of the probability of the occurrence of each anomaly in a rendered wall within the sample. The most frequent anomaly was dirt/particle deposits (A-E2), which presents a probability of $71 \%$ of developing in one wall rendering. It also shows that $92 \%$ of this anomaly occurs on external rendered surfaces, decreasing this probability to $30 \%$ in interior ones, which was expected given the respective types of exposure. Although this type of anomaly has a high frequency, according to Figure 4, which represents the gravity lev- els given for each anomaly in the sample, more than $90 \%$ of the cases do not present risk to the render's performance (level 2 - monitoring).

On the other hand, over $20 \%$ of linear cracking (A-M3) cases, which is the second commonest anomaly according to Figure 3, were assigned to level 0 repair urgency, meaning that an intervention to repair and consolidate the anomaly should be taken within 6 months (Fig. 4). This anomaly was found to have a probability of occurrence in a wall of $41 \%$ (Fig. 3) and presents just slightly higher probability of occurring in the external surfaces $(44 \%)$ than in the interior ones (34\%), which again agrees with specialised literature.

The anomalies scratches/grooves (A-M5), adherence loss/detachment (A-M1), biological colonisation (A-H2), infiltration/damp stains (A-H1) and colour change/discoloration (A-E4) have a considerable frequency $(26 \%$ to $35 \%$ ). Some idiosyncratic trends are worth noting, in particular anomaly A-M5 which occurs far more often in interior surfaces $(56 \%)$ than in external surfaces (11\%). The reason for this is that $50 \%$ of the interior surfaces inspected were from common circulation areas (32\%) and corridors $(18 \%)$, which are prone to this pathological occurrence. Furthermore, a high percentage of the façades inspected included a socle that protects the rendering from this anomaly.
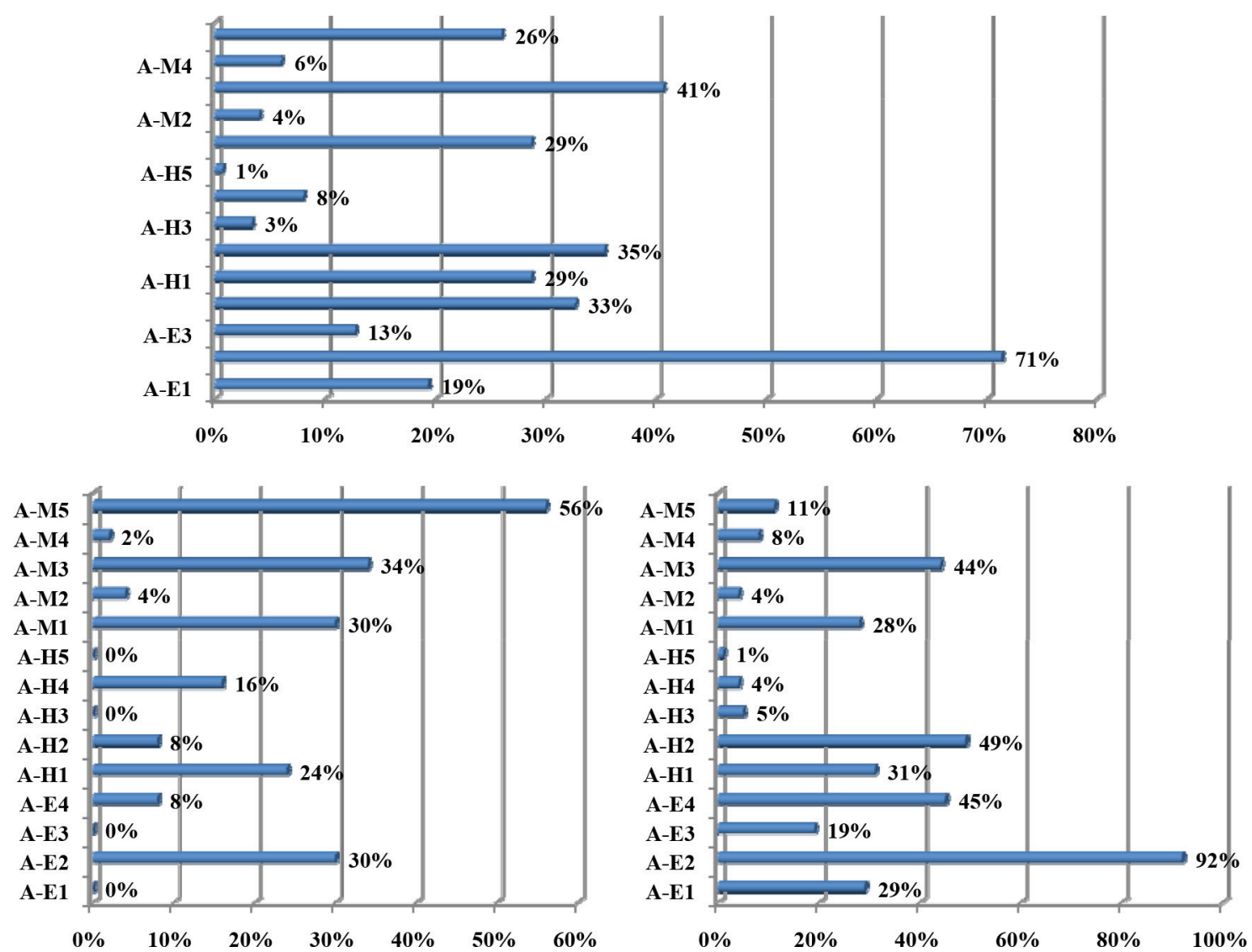

Fig. 3. Probability of finding each anomaly in one wall: consideringall surfaces (top), in interior surfaces (down left) and in external surfaces (down right) 


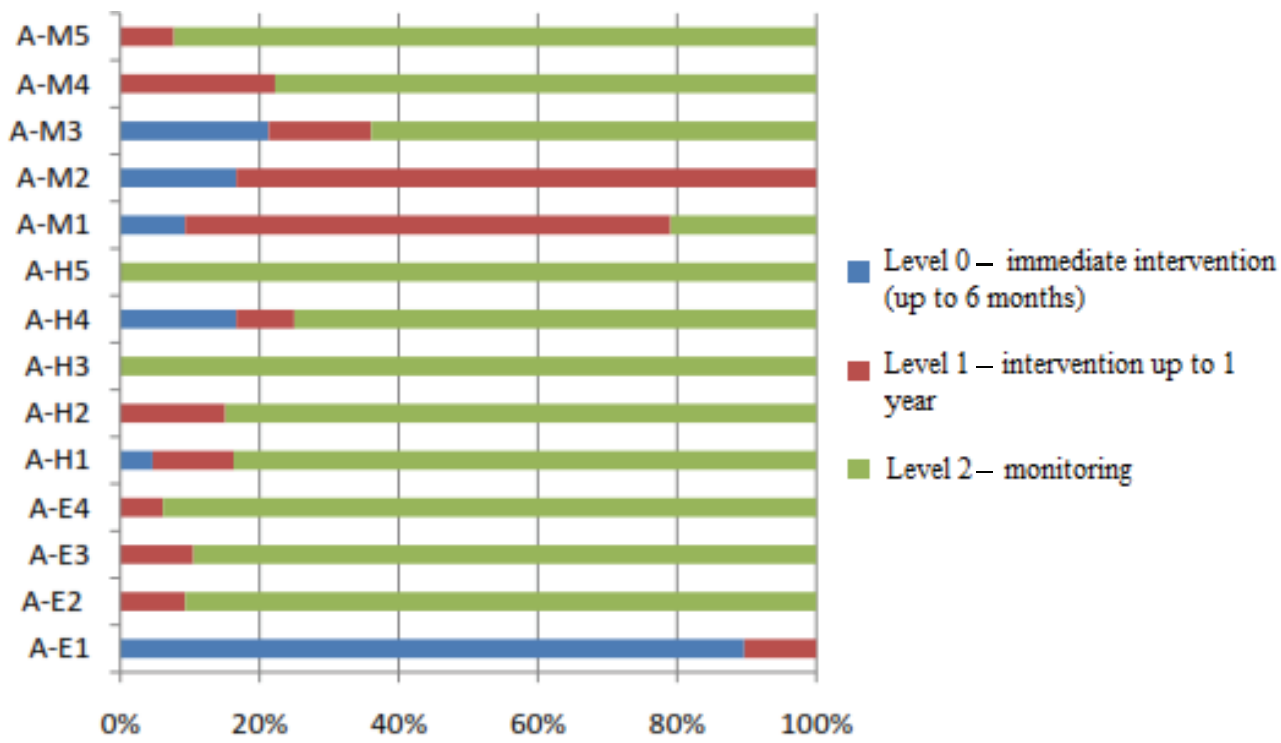

Fig. 4. Urgency to intervene/gravity of anomaly levels, according to the anomalies identified in the sample

As expected, biological colonisation (A-H2) owes its frequency $(35 \%)$ mostly to manifestations on external surfaces ( $49 \%$ versus $8 \%$ on interior surfaces), which is understandable since they are directly exposed to environmental action and typically difficult to access for cleaning, and are thus more prone to colonisation phenomena. Also, the absence of solar radiation, allowing humidity to settle and not dry in external walls is another aspect that influences de development of biological colonisation. Therefore, North orientated façades show higher presence of this anomaly, as shown in Figure 5 (which associates façade orientation with the occurrence of anomalies). Just like A-H2, colour change/discoloration (A-E4) occur much more on external surfaces (45\%) than interior ones (8\%) (Fig. 3) but, unlike the former, they are often associated with high solar incidence (which is one of the sources of colour changes), therefore presenting higher frequency in South orientated façades (Fig. 5).
Adherence loss/detachment (A-M1) and infiltration/ damp stains (A-H1) occur with similar frequency for interior and external surfaces and as often as each other (29\%) (Fig. 3). Adherence loss/detachment (A-M1) is very likely to interfere in the render's performance; therefore almost $80 \%$ of the found cases imply an intervention within a year (Fig. 4). External infiltration/damp stains (A-H1) (which consist of stains related to the presence of water) occur mostly in North orientated walls due to the lower sun incidence that would otherwise dry some of those stains (Fig. 5). These anomalies must be carefully monitored, in order to evaluate its development. If the stains continue to get worse with time, they will probably originate other types of anomalies. In fact, according to the inter-anomaly correlation matrix developed to provide statistical relationship between the occurrence of one anomaly, in the presence of another, lost of adherence (A-M1), loss of cohesion/ crumbling (A-M2), dirt/dust particle deposits (A-E2) and biological colonisation (A-H2) have between $40 \%$ and

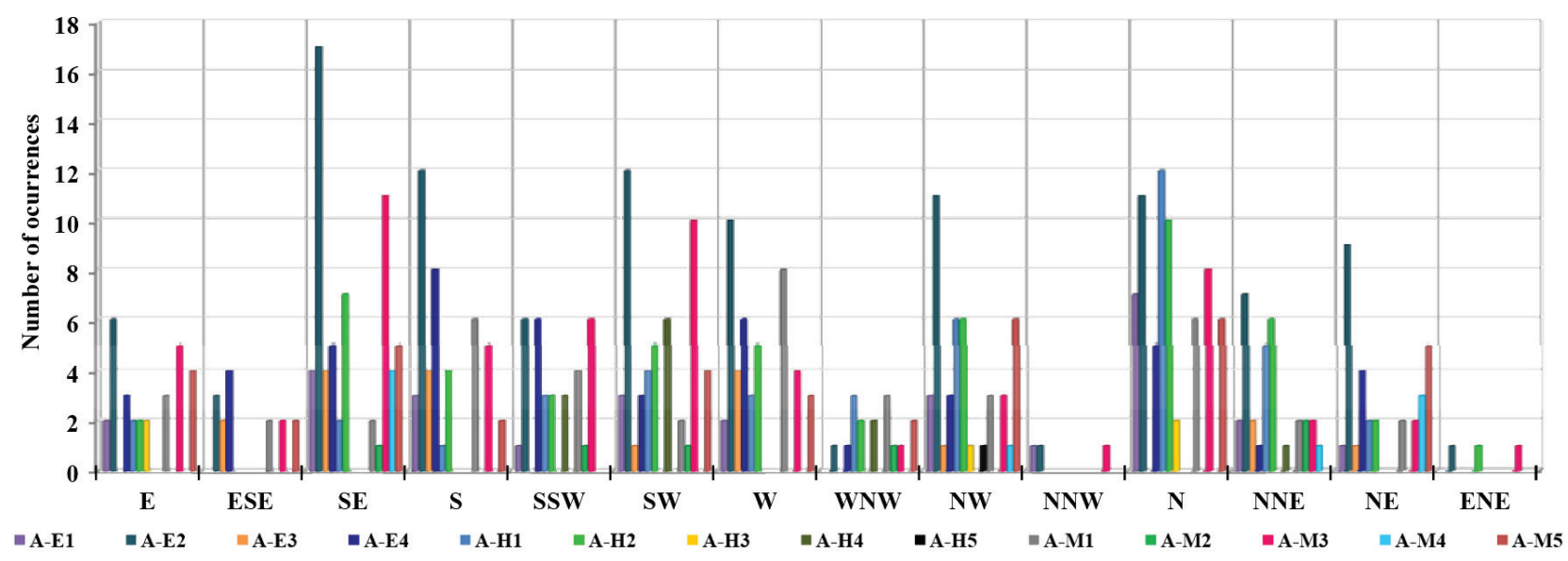

Fig. 5. Occurrence of each anomaly according to the façade orientation, within the sample 
$50 \%$ probability of occurring in the presence of infiltration/damp stains (A-H1).

Graffiti (A-E1), corrosion stains (A-E3), vegetation growth (A-H3) and carbonation (A-H5) characteristically only appear on external rendered surfaces, with a probability of occurrence of $19 \%, 13 \%, 3 \%$ and $1 \%$ respectively (Fig. 3). The anomaly Graffiti (A-E1) was given an intervention deadline of 6 months in $90 \%$ of the cases (level 0 of urgency to intervene - Fig. 4) because it may conceal other anomalies that must be treated and it becomes harder to eliminate the longer it remains. Since the first step of inspection is through visual appraisal, it is very important to be able to properly evaluate the wall renderings.

Efflorescence/cryptoflorescence (A-H4) occurs on $8 \%$ of the rendering inspected, with greater occurrence on interior surfaces $(16 \%)$ than in external ones $(4 \%)$ (Fig. 3). Since these anomalies are caused by the crystallisation of salts transported by water these statistics do not contradict the literature, because the water/humidity flux is predominantly from the exterior to the interior. Slightly over $20 \%$ of the cases were considered serious enough to prescribe an 1 year maximum intervention delay, due to the small area and its low effect on the render performance (Fig. 4), but it is important to keep monitoring the development of this phenomenon, since it may be the origin of other anomalies.

It is found that cohesion loss/crumbling (A-M2) occurs equally often on external and interior surfaces (4\%) and that map cracking (A-M4), as expected, occurs more on outer surfaces (8\%) than interior ones (2\%) (Fig. 3). This relates to the fact that environmental actions are more intense on the outside and application and curing conditions are less well controlled.

\subsection{Frequency of the causes}

As referred, the inspection and diagnosis system includes a classification list of causes of rendering anomalies. These are organized in five groups: design errors (C-C), execution errors (C-E), surrounding environment (C-M), mechanical actions (C-A) and wear and maintenance causes (C-U). During fieldwork for each anomaly one or more probable causes were registered, which further on allowed studying the origins of the anomalies. Figure 6 represents the contribution of each group of causes to the occurrence of anomalies in wall renderings, according to the fieldwork.

The results show that the greatest contributor is environmental actions (C-M), with $42 \%$ of occurrences. This was expected since most of the inspected renderings are external and therefore exposed to the aggressions of the environment throughout their service life. According to Figure 7, which presents the frequency of each cause related to the 476 anomalies found (organized by grouping), the study reveals that the commonest causes are airborne dirt particles (C-M1), wind and/or rain action (C-M3) and the presence of water/water vapour (C-M4). It is not surprising that these causes are related with the most common anomalies: A-E2 - dirt/particle deposits; A-H1 - infiltrations/damp stains; A-H2 - biological colonisation. The fact that almost half of the found causes for anomalies in wall rendering are environmental actions reinforces the importance of a good maintenance plan, in order to keep the correct performance of the wall render during its service life.

Other causes within the group that show a distinctly lower frequency are poor ventilation (C-M6) and reduced natural lighting/sun exposure or lack thereof (C-M7). These causes are less frequent because of their specificity; they are fundamentally indirect causes of infiltration/damp stains (A-H1) and biological colonisation (A-H2). This type of cause is a good example of the difference between direct and indirect causes, since poor ventilation is, for example, a consequence of bad interior design of the building.

In fact, design errors (C-C) were identified as the cause for $18 \%$ of the events and execution errors (C-E) for $15 \%$. Their frequency would certainly have been greater if more data would have been available on the design and execution stages of the renderings inspected. The anomalies found related to these causes might very

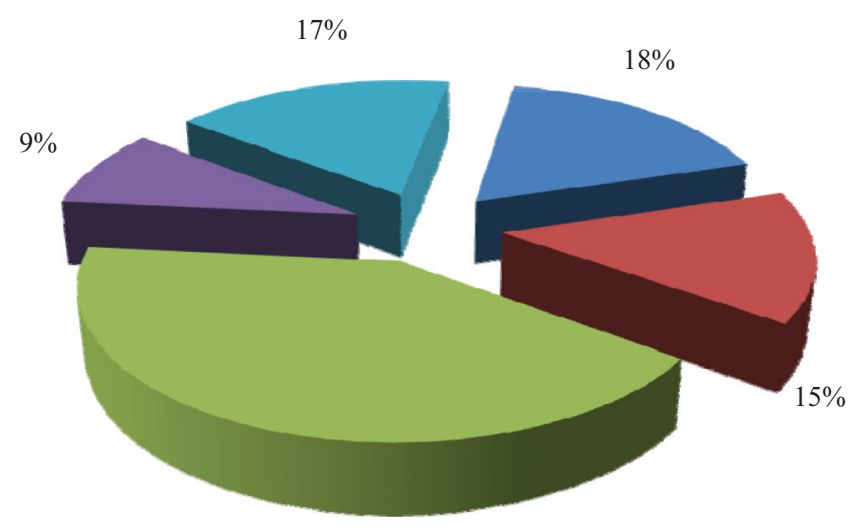

- C-C- Design errors

C-E- Execution errors

- C-M- Enviromental actions

- C-A- Mechanical actions

n-U- wear and maintenance faults

$42 \%$

Fig. 6. Relative contribution of each group of causes to the anomalies detected 

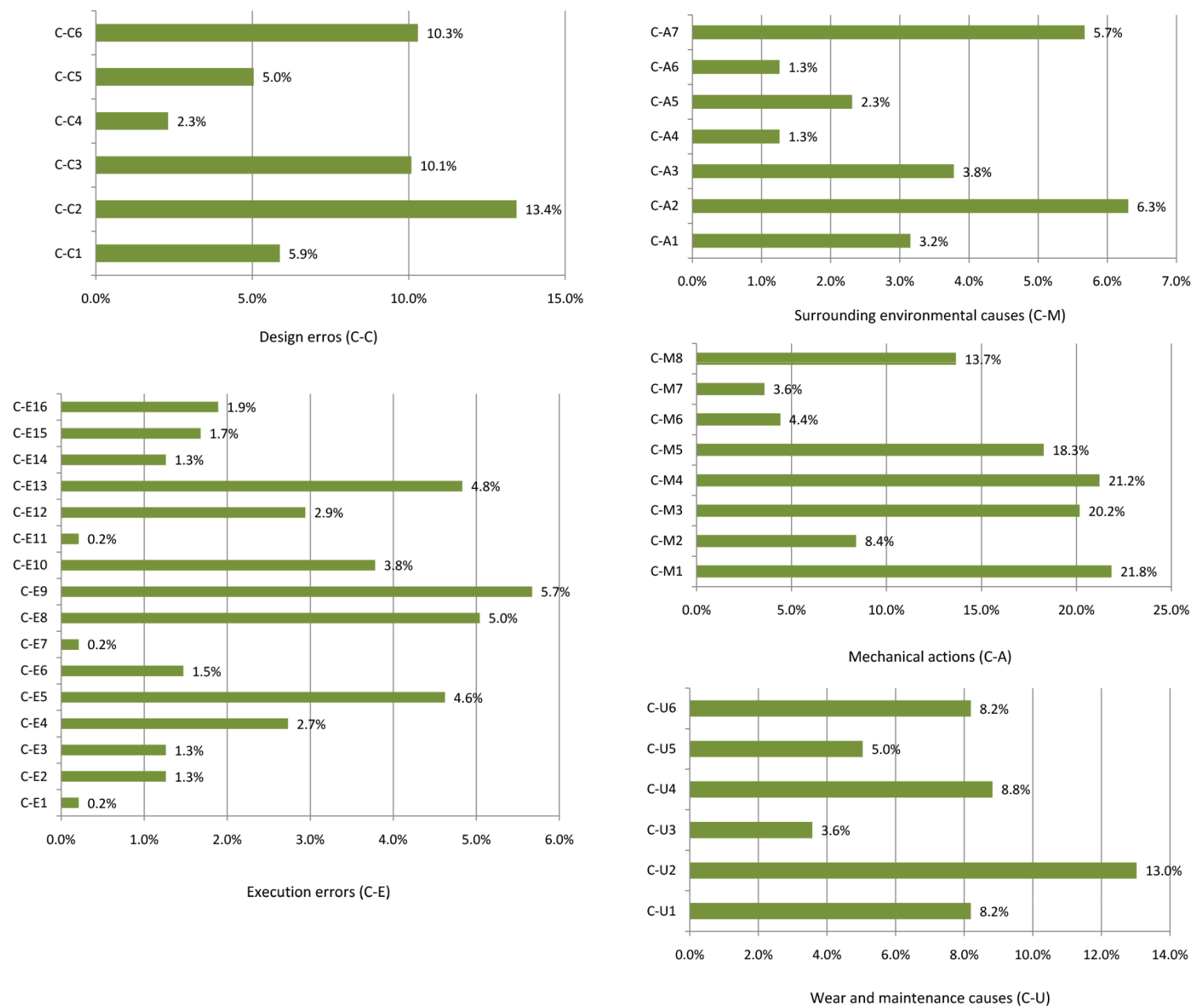

Fig. 7. Relative contribution of each group of causes to the anomalies detected

well be avoided if the design and application were properly executed and controlled.

The data shows the main concerns respecting design errors (C-C): the commonest causes are faulty design or lack of detailing (C-C2), faulty design or lack of gutters or water drainage systems (C-C3) and faulty specification of the products applied (C-C6), as a consequence of ignorance or negligence on the part of the designer concerning the characteristics and limitations of the materials, as well as the requirements demanded of the various coating systems. Related to execution errors (C-E), the most frequent causes are: inappropriate mortar composition (C-E5), corrosion of metal elements (C-E8), heterogeneity of supporting walls (C-E9) and inappropriate rendering texture (C-E13). These causes are associated with the anomalies that occur most often in renderings (A-E2 - dirt/particle deposits and A-M3 - linear cracking), which explains their preponderance.

Some execution errors have low frequencies due to the limited access to information about the work's stage, such as: C-E1 - use of inexperienced/unqualified workmanship; C-E2 - lack of compliance with design and/ or building and construction specifications; C-E3 - use of dirty tools during construction; C-E7 - excess water/ moisture in construction; C-E11 - rendering applied in adverse weather conditions; C-E14 - lack of monitoring of the rendering during curing.

Mechanical actions (C-A) are the ones least represented in the sample, with less than $9 \%$ of the occurrences. The causes within the group show roughly uniform frequencies, even though shocks/bumping (C-A2) and stress concentration (C-A7) have higher frequencies and supporting wall shrinkage (C-A4) and structural motions (settlement and deformation) (C-A6) have lower frequencies. This last trend is related to the type of buildings inspected, their state of repair and the type of inspections performed. The buildings are all occupied as dwellings or as shops and signs of evident structural motion were rare. The inspections were based on visual observation of the surfaces, so any shrinkage of the substrate not visible on the surface and more subtle structural motions (only identifiable through a deeper inspection of the structural elements and a specialised study of geological, hygrothermal and dynamic actions) were not identified; as a result, anomalies that could have been related were associated with other causes.

Wear and maintenance faults $(\mathrm{C}-\mathrm{U})$ represent around $17 \%$ of all causes detected in the inspection campaign. In this group the most frequent cause was irregular re- 
painting (C-U2), associated with frequent anomalies such as dirt/particle deposits (A-E2), colour change/discoloration (A-E4) and scratches/grooves (A-M5), which explains this high frequency. The causes in the second level of frequency are irregular cleaning/washing (C-U1), haphazard actions related to user occupation, traffic and wear (C-U4) and vandalism (C-U6), associated with graffiti (A-E1), dirt/particle deposits (A-E2), biological colonisation (A-H2) and scratches/grooves (A-M5).

\subsection{Frequency of the diagnosis methods}

Figure 8 presents the results of the data analysis for the prescribed diagnosis methods. Not surprisingly the most frequent is visual inspection and macroscopic analysis (D-I1), prescribed in every instance. This also concerns the nature of the inspections performed, based solely on visual observation.

The humidity meter (D-H3) was the second most frequently prescribed method, for $1 / 5$ of the instances. It is associated with the detection of humidity on the surface, which justifies its high frequency since dampness in renderings encourages the development of a great variety of anomalies. Even though with much lower frequencies ( $7 \%$ and $6 \%$ respectively) the speedy moisture tester (D-H4) and the Karsten-tube (D-P1) stand out from the others for the same reason as method D-H3. Infrared thermography (D-D3) has a similar frequency to these last methods and is also related to damp surface areas. Finally, the crack comparison chart (D-F1) with $9 \%$ and optical crack meter (D-F2) with $6 \%$ complete the most prescribed diagnosis methods. These two methods are related to cracking diagnosis, which was the second most frequent anomaly in the inspection campaign, thereby explaining these figures.

The use of the thermometer (D-H1) and the hygrometer (D-H2) were proposed mostly to diagnose anomalies in indoor rooms where water vapour/moisture was commonly found, such as kitchens and bathrooms. The lower frequency of these methods compared with that of D-H3 is due to their specificity and the lower incidence of interior renderings $(1 / 3)$ in the sample.
The abrasion test (D-R4) and pendulum sclerometer (D-R5) were proposed for $1 / 3$ of the occurrences of adherence loss/detachment (A-M1) to evaluate the resistance of the rendering to friction and impact. The sphere shock test (D-R1) was proposed less often because it can only be used when the state of the anomaly allows, since it is a destructive test and may aggravate the anomaly.

The resistance diagnosis tests (D-R), especially the sphere shock test (D-R1) and the scratch test (D-R3), are frequently associated with scratches/grooves (A-M5), because they most closely reproduce the commonest actions that cause this anomaly.

The least frequently proposed method is the phenolphthalein indicator (D-S4), which is prescribed only to diagnose carbonation (A-H5). The low frequency of this method is due to the very small number of carbonation cases found (only 1 out of the 476 anomalies detected), not to the method being inadequate. The next method is testimony testing (D-F3), whose low frequency is due to its association with live cracks that were rarely identified and for which the crack meter (D-F4) can also be prescribed with the advantage that it gives quantitative results. As for micro-perforation (R-D6) and controlled penetration (R-D7), they are used to determine the interior strength of the rendering and since method D-R7 is more expedient and less onerous it is naturally prescribed more often.

The magnetometer (D-M1) has a low frequency because it was only prescribed when it was thought that there were metal elements inside the rendering that could have led to the anomalies detected. This method proved to be valuable at resolving some doubts that arose during the inspections.

The ultrasound test (D-D1) was the only one not prescribed during the inspection programme. It was expected to be useful in detecting loss of material, voids and heterogeneity within the renderings and therefore this situation was only due to the size of the sample and because it was thought that the method would not bring added value to any of the cases analysed. Finally, the low frequency of the titrimetric analysis (D-S2) and of the co-

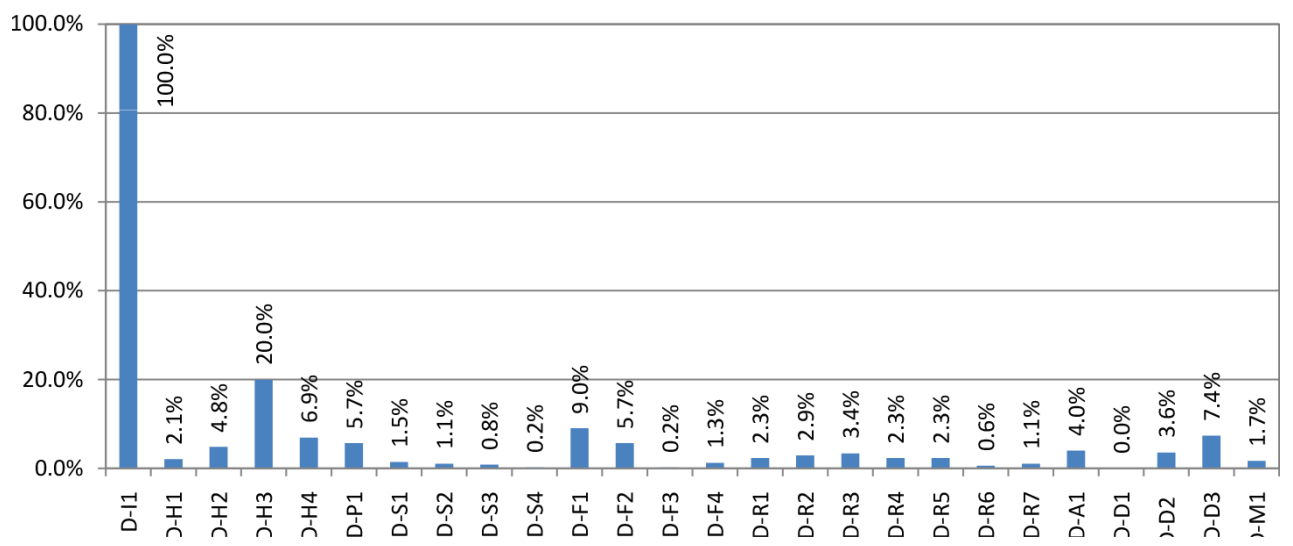

Fig. 8. Relative frequency of the diagnosis methods proposed 
lour analysis (D-S3), both identifying the same anomaly, was due to there being another more expedient and easier to perform salts diagnosis method: the colour comparison test strip (D-S1).

\subsection{Frequency of the repair techniques}

Figure 9 collects the inspection data and denote a clear predominance of repair technique full/partial replacement of the finish (top or finishing layer) (R-B2) (21.8\%). This was followed by cleaning (R-A1) (17.8\%), full/partial replacement of the rendering $(\mathrm{R}-\mathrm{C} 1)$ and application of new finishing over existing rendering (R-B3) (both with $15.1 \%$ ), which is consistent with the sample where the anomalies most represented were scratches/grooves (A-M5) on interior renderings and dirt/particle deposits (A-E2) on external renderings.

The high frequency of technique R-A1 (17.8\%) is linked to its versatility and ability to suppress most of the aesthetic and moisture-related anomalies, the ones most represented in the sample, especially dirt/particle deposits (A-E2) - 22\% just by itself. The predominance of technique R-B2 (21.8\%) is in line with the literature because it has the same function as cleaning (R-A1), the second most frequent technique, but it is more efficient and therefore can be used for all anomalies whose depth does not extend beyond the finishing layer. The only remark about this technique is that its efficiency depends on how accurately the depth of rendering affected is determined. A high frequency (15.1\%) was also expected for the full/partial replacement of the rendering ( $\mathrm{R}-\mathrm{C} 1)$ since it is a last resort that eliminates practically any anomaly. However, it is also a very costly and onerous solution. The high frequency (15.1\%) of technique R-B3 was a big surprise since it was not expected based on experience or the literature.

The correction of geometric construction features (R-D1) and the application of surface protection (R-A3) exhibit considerable frequencies $(8.2 \%$ and $7.5 \%$ respectively). The first was more or less expected, bearing in mind the present situation of designers' lack of technical expertise, which is also noticed during the on-site execution stage. The second is explained by the technique's versatility, both corrective and preventive, which increases the number of cases for which it is prescribed.

The filling and elimination of cracks (R-B1), although less frequently prescribed than the previous ones
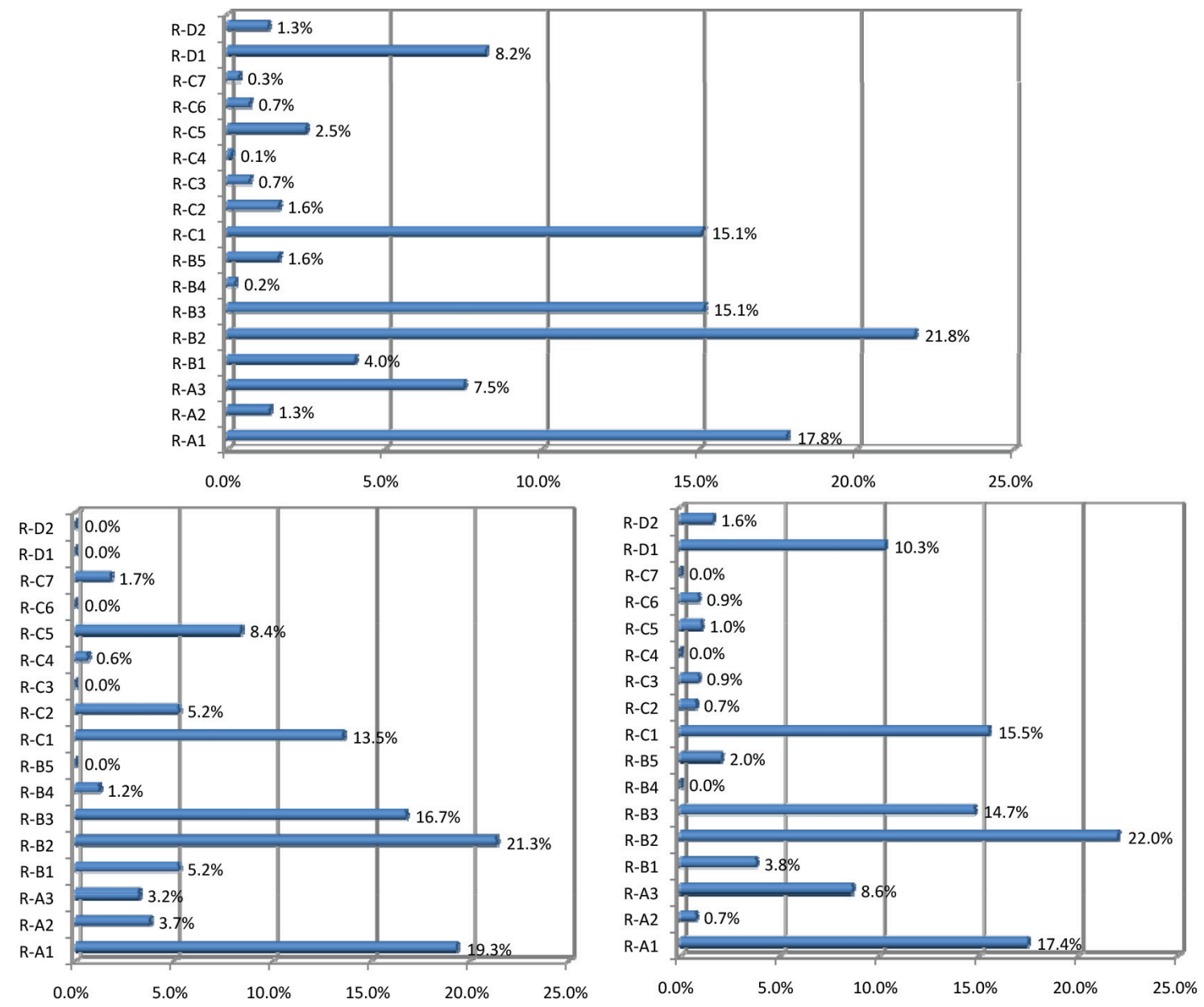

Fig. 9. Frequency of each repair technique predicted in the sample: considering all surfaces (top), in interior surfaces (down left) and in external surfaces (down right) 
$(4 \%)$, is quite suitable, bearing in mind the lower frequency of the anomalies for which it is prescribed.

The maintenance/removal of corroded metal elements (R-D2) was only recommended rarely, which reveals both its specificity and the increasing scarcity of unprotected metal elements in modern buildings. The cases registered concerned mostly older buildings and the frequency decreases with the decreasing age of the buildings.

The frequencies of the techniques protection of salient corners (R-A2), creation of joints over live cracks (R-B5), application of a reinforced rendering (R-C2) and application of a new coating of rendering over the existing rendering (R-C5) demonstrate their reasonable adequacy and are consistent with the frequency of the corresponding anomalies in the sample.

The rare occurrence of the techniques application of a moisture barrier to interior face walls (R-B4), execution of an External Thermal Insulation Compound System (ETICS) (R-C3), execution of a reinforced rendering coating independently of the supporting wall (R-C4), application of a rendering of higher thermal performance grade (R-C6) and application of drainage or corrective rendering (R-C7) denotes their specificity, but is in agreement with the frequency of the corresponding anomalies in the sample.

\subsection{Repair techniques-anomalies relationship}

Figure 10 results from cross-referencing data concerning the anomalies and repair techniques prescribed, allowing the study of relationships between them.

For graffiti (A-E1) there are four techniques in very similar terms: cleaning (R-A1); application of surface protection (R-A3); full/partial replacement of the finish (top or finishing layer) (R-B2); and application of new finishing over existing rendering (R-B3). Any of these techniques is technically viable and the choice is going to depend on the available budget and the targeted final result.
The techniques most prescribed for dirt/particle deposits (A-E2) were cleaning (R-A1) and the application of new finishing over existing rendering (R-B3); the choice between them is conditioned by the gravity level and the state of development of the anomaly. Close behind comes full/partial replacement of the finish (top or finishing layer) (R-B2), because it is slightly more expensive and is suitable when the anomaly is developing in such a way that the other techniques do not guarantee a good final result. Then comes the correction of geometric construction features (R-D1) which, even though slightly more specific, is still quite common, again denoting a lack of technical knowledge of many designers with respect to façade detailing. Finally, the techniques application of surface protection (R-A3), execution of an External Thermal Insulation Compound System (ETICS) (R-C3) and application of a rendering of higher thermal performance grade (R-C6) have narrow ranges of application that translate into low frequency.

Cleaning (R-A1), full/partial replacement of the finish (top or finishing layer) (R-B2), application of new finishing over existing rendering (R-B3), correction of geometric construction features (R-D1) and maintenance/ removal of corroded metal elements (R-D2) are the techniques most prescribed for corrosion stains (A-E3), with technique R-B3 slightly below the others because it is not always possible to apply a new coating over the existing one. The application of surface protection (R-A3) and full/partial replacement of the rendering (R-C1) are also possible but used much less often. The first is essentially preventive but does not really repair the anomaly. The second is more aggressive and often seen as excessive, unless the corroded elements have already compromised the rendering's cohesion.

The techniques most prescribed for colour change/ discoloration (A-E4) were full/partial replacement of the finish (top or finishing layer) (R-B2) and application of

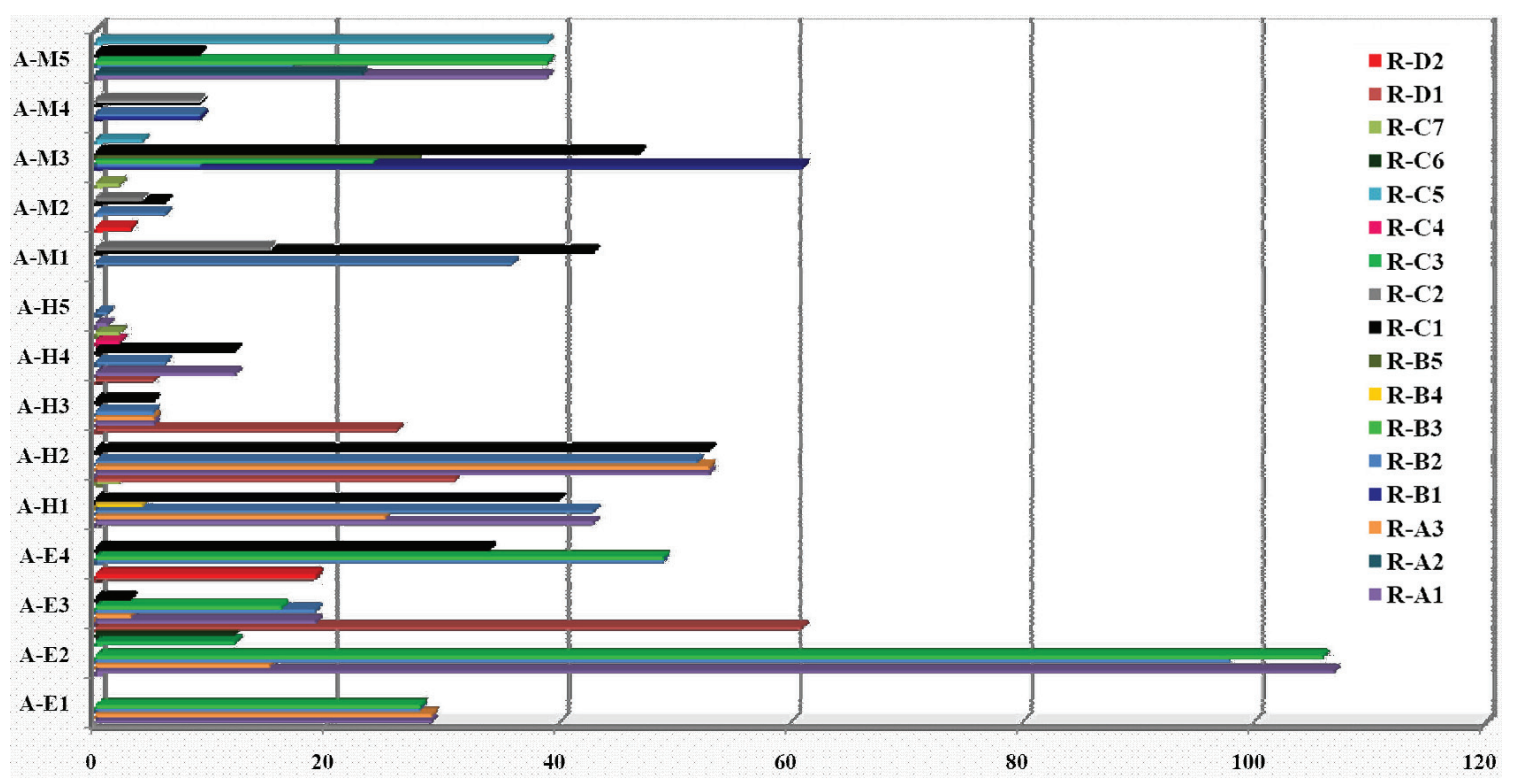

Fig. 10. Absolute frequency of each repair technique as a function of the anomaly type 
new finishing over existing rendering (R-B3), alternatives clearly used with equal frequency. The full/partial replacement of the rendering ( $\mathrm{R}-\mathrm{C} 1)$ shows a lower frequency because it is costlier and tends to be seen as excessive.

The most frequently prescribed techniques for infiltration/damp stains (A-H1) were cleaning (R-A1) and full/partial replacement of the finish (top or finishing layer) (R-B2), followed by full/partial replacement of the rendering ( $\mathrm{R}-\mathrm{C} 1)$, which deals with deeper problems and is suitable mostly for direr situations when the integrity of the rendering is affected. The techniques correction of geometric construction features (R-D1) and application of surface protection (R-A3) were less prescribed since they have a more focused scope of application and more preventive than corrective nature, respectively. The application of a moisture barrier to interior face walls (R-B4) and the application of drainage or corrective rendering (R-C7) are seldom prescribed due to their limited scope of use.

The techniques most prescribed to eliminate biological colonisation (A-H2) were cleaning (R-A1), application of surface protection (R-A3), full/partial replacement of the finish (top or finishing layer) (R-B2) and full/partial replacement of the rendering (R-C1), with similar frequency. Then comes the correction of geometric construction features (R-D1) with a frequency around half of the previous ones, because it sometimes eliminates the source of the anomaly and not really the anomaly itself.

The techniques considered most appropriate to cope with vegetation growth (A-H3) were cleaning (R-A1), application of surface protection (R-A3), full/partial replacement of the finish (top or finishing layer) (R-B2), full/partial replacement of the rendering (R-C1) and correction of geometric construction features (R-D1), somewhat unexpectedly all with the same frequency. For example technique $\mathrm{R}-\mathrm{C} 1$ is used when the anomaly is characterised by roots penetrating the rendering. Technique R-D1, however, which cannot itself eliminate the anomaly, is used to correct some types of detailing (corners, niches, garrets) where parasitic vegetation tends to thrive.

The techniques most frequently prescribed to repair/ eliminate efflorescence/cryptoflorescence phenomena (A-H4) were cleaning (R-A1) and full/partial replacement of the rendering (R-C1), with the same incidence. The first is more associated with efflorescence and the second with cryptoflorescence. Slightly below comes full/partial replacement of the finish (top or finishing layer) (R-B2), which proves to be the best technique when the prolonged occurrence of these phenomena has degraded the coating's surface and cleaning is not enough to restore its original state. Finally, there are the techniques execution of a reinforced rendering coating independently of the supporting wall (R-C4) and application of drainage or corrective rendering (R-C7). These have very low frequency due to their narrow scope of application.
Techniques prescribed for carbonation phenomena (A-H5) were cleaning (R-A1) and full/partial replacement of the finish (top or finishing layer) (R-B2). This anomaly is hard to identify and is easily mistaken for efflorescence (A-H4); therefore it was seldom identified in the fieldwork, hence it may considered that the sample is not statistically relevant for this anomaly.

The technique most often prescribed to correct adherence loss/detachment (A-M1) was full/partial replacement of the rendering (R-C1). This could be considered too deep an intervention but in most cases during the inspections this anomaly was associated with cohesion loss/crumbling (A-M2). With a slightly lower frequency comes full/partial replacement of the finish (top or finishing layer) (R-B2), for the cases other than the previous ones. Applying a reinforced rendering (R-C2) is prescribed much less often in those cases where the substrate seems unstable or as a means of avoiding the repetition of the same defects (re-pathology). Finally there were isolated cases where the maintenance/removal of corroded metal elements (R-D2) was prescribed to eliminate the main cause of this anomaly.

Cohesion loss/crumbling (A-M2) were dealt with by prescribing full/partial replacement of the finish (top or finishing layer) (R-B2), full/partial replacement of the rendering ( $\mathrm{R}-\mathrm{C} 1)$ and application of a reinforced rendering ( $\mathrm{R}-\mathrm{C} 2)$. The use of technique R-B2 here is explained by the need to fully replace the rendering after correcting this anomaly, to prevent aesthetically unacceptable results. The application of drainage or corrective rendering (R-C7) is also associated with A-M2 but with low frequency, because of its narrow application scope.

As expected, linear cracking (A-M3) was mostly dealt with by prescribing the filling and elimination of cracks (R-B1), followed by full/partial replacement of the rendering ( $\mathrm{R}-\mathrm{C} 1)$, a more intrusive technique that guarantees better success in the most critical cases. Next comes the creation of joints over live cracks (R-B5) and the application of new finishing over existing rendering (R-B3), prescribed with considerable frequency, notwithstanding their narrow scope. Finally, the techniques full/ partial replacement of the finish (top or finishing layer) (R-B2) and application of a new coating of rendering over the existing rendering (R-C5) show much lower frequencies, due to too-narrow fields of application.

As for map cracking (A-M4), the techniques most prescribed were filling and elimination of cracks (R-B1), full/partial replacement of the finish (top or finishing layer) (R-B2), full/partial replacement of the rendering (R-C1) and application of a reinforced rendering (R-C2) with similar frequencies, which indicates that the sample was evenly distributed in terms of cracking phenomena. While technique R-B1 can be used in almost every case $\mathrm{R}-\mathrm{B} 2$ is for superficial cracking, and $\mathrm{R}-\mathrm{C} 1$ and $\mathrm{R}-\mathrm{C} 2$ are suitable for more serious situations with deeper cracking and localised adherence losses. 
The analysis of the data shows that the techniques most often prescribed to deal with scratches/grooves (A-M5) were cleaning (R-A1), application of new finishing over existing rendering (R-B3) and application of a new coating of rendering over the existing rendering (R-C5). This was expected since this type of anomaly generally does not compromise the rendering at depth. Next come protection of salient corners (R-A2) and full/ partial replacement of the finish (top or finishing layer) (R-B2), with a still significant but lower frequency: RA-2 because it is both a preventive and a corrective technique and has a limited scope of application; RB-2 because it is still a technical-economically valid solution, even though not as much as R-B3. Finally, the full/partial replacement of the rendering (R-C1) is barely mentioned because it is normally an excessive solution for this anomaly.

\section{Conclusions}

There are some specialised systems to evaluate damage and anomalies in construction materials and elements. Although there has been an extensive effort in the research of this type of material, no work similar to this in terms of scope and objective was found in the literature. The authors propose a system simultaneously innovative, robust and viable and supported by a large statisticallyrelevant validation programme. The systematic approach used to build this knowledge-based inspection tool and implement it in an inspection programme can help inspectors in their on-site work and make their activities more objective and procedures more standardised.

The system and its basic pillars were calibrated and validated based on a sample of 55 buildings inspected, with a grand total of 150 wall renderings (100 external and 50 interior). The statistical analysis performed demonstrates its unquestionable value to practitioners, from the design stage to the application of the solutions devised. It is also concluded that a continued process of surveying and registering anomalies in wall renderings will enable reliable degradation models to be built, and so the bigger the size and variety of the sample analysed the better. The statistical data obtained here supplement similar studies on other non-structural construction elements, from the same research team (Silvestre, de Brito 2011; Palha et al. 2012; Pereira et al. 2014; Garcez et al. 2012).

\section{References}

Araújo, A. 2002. Pathologies in new buildings - identification, repair solutions and preventive measures, in $X X X$ IAHS World Congress on Housing, 9-13 September 2002, University of Coimbra, Portugal, vol. 3, 1985-1992.

Binda, L.; Cardani, G.; Zanzi, L. 2010. Non-destructive testing evaluation of drying process in flooded full-scale masonry walls, Journal of Performance of Constructed Facilities 24 (Special issue: Flood Impact to Heritage Structures): 473-483.

Candel, R.; Fernandez, S.; Anchuela, I. 1997. Manual de mantenimiento de edificios. El libro del técnico mantenedor. Consejo Superior de Los Colegios de Arquitectos de España.
Flores-Colen, I.; de Brito, J.; Freitas, V. 2008. Stains in facades rendering - diagnosis and maintenance techniques' classification, Construction and Building Materials 22(3): 211-221. http://dx.doi.org/10.1016/j.conbuildmat.2006.08.023

Flores-Colen, I.; de Brito, J.; Freitas, V. 2009. Expected rendering performance based on in-field assessment - impact resistance, Construction and Building Materials 23(9): 2997-3004.

http://dx.doi.org/10.1016/j.conbuildmat.2009.05.003

Flores-Colen, I.; de Brito, J.; Freitas, V. 2011. On-site performance assessment of rendering façades for predictive maintenance, Structural Survey 29(2): 133-146. http://dx.doi.org/10.1108/02630801111132812

Freire, L.; de Brito, J. 2006. Relationship between bearings type and their most common anomalies, in Third International Conference on Bridge Maintenance, Safety and Management (IABMAS’ 06), IABMAS, 2006, Porto, Portugal, paper 10 .

Garcez, N.; Lopes, N.; de Brito, J.; Silvestre, J. 2012. System of inspection, diagnosis and repair of external claddings of pitched roofs, Construction and Building Materials 36: 807-819.

http://dx.doi.org/10.1016/j.conbuildmat.2012.06.049

Gaspar, P.; de Brito, J. 2005. Mapping defect sensitivity in external mortar renders, Construction and Building Materials 19(8): 571-578.

http://dx.doi.org/10.1016/j.conbuildmat.2005.01.014

Gaspar, P.; de Brito, J. 2011. Limit states and service life of cement renders on façades, Journal of Materials in Civil Engineering 23(10): 1396-1404.

http://dx.doi.org/10.1061/(ASCE)MT.1943-5533.0000312

Hernández-Olivaresa, F.; Mayor-Lobo, P. 2011, Experimental assessment of commercial one-coat renders for buildings façades, Construction and Building Materials 25(1): $156-162$.

http://dx.doi.org/10.1016/j.conbuildmat.2010.06.044

Norvaišiene, R.; Burlingis, A.; Stankevičius, V. 2004. Durability of the painted rendered facades, when introducing artificial acidic rain solution, Journal of Civil Engineering and Management 10(4): 295-302.

http://dx.doi.org/10.1080/13923730.2004.9636322

Pacheco-Torgal, F.; Faria, J.; Jalali, S. 2012. Some considerations about the use of lime-cement mortars for building conservation purposes in Portugal: a reprehensible option or a lesser evil?, Construction and Building Materials 30: 488-494. http://dx.doi.org/10.1016/j.conbuildmat.2011.12.003

Palha, F.; Pereira, A.; de Brito, J.; Silvestre, J. D. 2012. Effect of water on the degradation of gypsum plaster coatings: inspection, diagnosis and repair, Journal of Performance of Constructed Facilities 26(4): 424-432. http://dx.doi.org/10.1061/(ASCE)CF.1943-5509.0000258

Pavlíková, M.; Pavlík, Z.; Keppert, M.; Černý, R. 2011. Salt transport and storage parameters of renovation plasters and their possible effects on restored buildings' walls, Construction and Building Materials 25(3): 1205-1212.

Pereira, A.; Palha, F.; de Brito, J.; Silvestre, J. 2014. Inspection, pathological characterization, diagnosis and repair of inner gypsum plaster on walls and ceilings, Journal of Civil Engineering and Management 20(4): 485-496. http://dx.doi.org/10.3846/13923730.2013.801918

Sá, G.; Sá, J.; de Brito, J. 2014. Inspection and diagnosis system for rendered walls, International Journal of Civil Engineering 12(2): 279-290.

Schueremans, L.; Cizer, Ö.; Janssens, E.; Serré, G.; Van Balen, K. 2011. Characterization of repair mortars for the assessment of their compatibility in restoration projects: research and practice, Construction and Building Materials 25(12): 4338-4350. http://dx.doi.org/10.1016/j.conbuildmat.2011.01.008 
Silva, V. 2004. Practical guide for the conservation of buildings. Secretariat of State of Housing, Lisbon, Portugal.

Silvestre, J.; de Brito, J. 2011. Ceramic tiling in building facades: Inspection and pathological characterization using an expert system, Construction and Building Materials 25(4): $1560-1571$.

http://dx.doi.org/10.1016/j.conbuildmat.2010.09.039
Vallens, K.; Bescher, E.; Mackenzie, J. D.; Rice, E. 2001. A new technique for the measurement of the impact resistance of wall coatings, Cement and Concrete Research 31(6): 965-968.

http://dx.doi.org/10.1016/S0008-8846(01)00505-1

Veiga, R. 2000. Influence of application conditions on the cracking susceptibility of renderings, RILEM Publications S.A.R.L., Concrete Science and Engineering 2: $134-140$

\section{LIST OF ACRONYMS}

(Refer to: Sá et al. 2014; Gaspar, Brito 2005; Flores-Colen et al. 2008 for a detailed description of the terms presented)

A-E aesthetic anomalies

A-E1 graffiti

A-E2 dirt/particle deposits

A-E3 corrosion stains

A-E4 colour change/discoloration

A-H anomalies associated with moisture

A-H1 infiltration/damp stains

A-H2 biological colonisation

A-H3 vegetation growth

A-H4 efflorescence/cryptoflorescence

A-H5 carbonation

A-M mechanically-related anomalies

A-M1 adherence loss/detachment

A-M2 cohesion loss/crumbling

A-M3 linear cracking

A-M4 map cracking

A-M5 scratches/grooves

C-C design errors

C-C1 faulty application of regulations and tenders

C-C2 faulty design or lack of detailing

C-C3 faulty design or lack of gutters or water drainage systems

C-C4 faulty design or lack of heat insulation in walls

C-C5 faulty design or lack of reinforcement systems for protection against mechanical action

C-C6 faulty specification of the products applied

C-E execution errors

C-E1 use of inexperienced/unqualified workmanship

C-E2 lack of conformity to design and/or building and construction specifications

C-E3 use of dirty tools during construction (contamination)

C-E4 presence of water-soluble salts in moisture or in the materials employed

C-E5 inappropriate mortar composition

C-E6 excessive fines content

C-E7 excess water/moisture in construction (mortar and/or supporting walls)

C-E8 corrosion in metal elements (embedded in the rendering or affixed to its surface)

C-E9 heterogeneity of supporting walls

C-E10 faulty preparation of supporting walls (cleaning, roughness, wetness)
C-E11 rendering applied under adverse weather conditions

C-E12 inadequate rendering thickness

C-E13 inadequate rendering texture

C-E14 lack of monitoring of the rendering during curing

C-E15 lack of sufficient water vapour permeability in rendering or painting

C-E16 use of dark colours in external walls

C-M environmental actions

C-M1 air-borne dirt particles

C-M2 solar radiation/temperature action

C-M3 wind and/or rainwater action

C-M4 presence of water/water vapour

C-M5 high relative humidity ( $\mathrm{RH}>70 \%)$

C-M6 poor ventilation

C-M7 reduced natural lighting/sun exposure or lack thereof

C-M8 natural wear and tear

C-A mechanical actions

C-A1 abrasion

C-A2 shocks/bumping

C-A3 wall cracking (propagation to the rendering)

C-A4 supporting wall shrinkage

C-A5 rendering shrinkage

C-A6 structural motions (settlement and deformation)

C-A7 stress concentration

C-U wear and maintenance faults

C-U1 irregular cleaning/washing

C-U2 irregular repainting

C-U3 poorly executed maintenance works/minor repairs

C-U4 accidental actions related to user occupation, traffic and wear

C-U5 lack of fittings (piping, drains, gutters, rainwater vertical piping)

C-U6 vandalism

D-I preliminary diagnosis

D-I1 visual inspection and macroscopic analysis

D-H moisture diagnosis

D-H1 thermometer

D-H2 hygrometer

D-H3 humidity meter

D-H4 speedy moisture tester 


\begin{tabular}{|c|c|c|c|}
\hline D-P & permeability diagnosis & R-A & rendering surface \\
\hline D-P1 & Karsten-tube penetration test & R-A1 & cleaning \\
\hline D-S & salts diagnosis & R-A2 & protection of salient corners \\
\hline D-S1 & colour comparison test strip & R-A3 & application of surface protection \\
\hline D-S2 & titrimetric analysis & R-B & finishing layer \\
\hline D-S3 & colour analysis & R-B1 & filling and elimination of cracks \\
\hline D-S4 & phenolphthalein indicator & R-B2 & full/partial replacement of the finish (top or fin- \\
\hline D-F & cracking diagnosis & & ishing layer) \\
\hline D-F1 & crack comparison chart & R-B3 & application of new finishing over existing ren- \\
\hline D-F2 & optical crack meter & & dering \\
\hline D-F3 & testimony testing & R-B4 & application of a moisture barrier to interior face \\
\hline D-F4 & crack meter & & walls \\
\hline D-R & resistance diagnosis & R-B5 & creation of joints over live cracks \\
\hline D-R1 & sphere shock test & R-C & rendering system \\
\hline D-R2 & grid testing & R-C1 & full/partial replacement of the rendering \\
\hline D-R3 & scratch test & R-C2 & application of a reinforced rendering \\
\hline D-R4 & abrasion test & R-C3 & execution of an external thermal insulation com- \\
\hline D-R5 & pendulum sclerometer & & pound system (ETICS) \\
\hline D-R6 & micro-perforation & R-C4 & execution of a reinforced rendering coating in- \\
\hline D-R7 & controlled penetration & & dependently of the supporting wall \\
\hline D-A & adherence diagnosis & R-C5 & application of a new coating of rendering over \\
\hline D-A1 & pull-off test & & the existing rendering \\
\hline D-D & $\begin{array}{l}\text { diagnosis of discontinuities and hidden } \\
\text { anomalies }\end{array}$ & R-C6 & $\begin{array}{l}\text { application of a rendering of higher thermal per- } \\
\text { formance grade }\end{array}$ \\
\hline D-D1 & ultrasound test & R-C7 & application of drainage or corrective rendering \\
\hline D-D2 & percussion test & R-D & envelope \\
\hline D-D3 & infrared thermography & R-D1 & correction of geometric construction features \\
\hline D-M & detection of metal elements & R-D2 & maintenance/removal of corroded metal \\
\hline D-M1 & magnetometer & & element \\
\hline
\end{tabular}

Gonçalo SÁ. Holds a Master's degree in Civil Engineering from Instituto Superior Técnico, Technical University of Lisbon, Portugal. His research interests include the life cycle of construction elements.

João SÁ. Holds a Master’s degree in Civil Engineering from Instituto Superior Técnico, Technical University of Lisbon, Portugal. His research interests include the life cycle of construction elements.

Jorge DE BRITO. Is a Full Professor at Instituto Superior Técnico, Technical University of Lisbon, Portugal. He is a member of CIB W80, W86 and W115. He is the author of 2 international books and 120 plus papers in international referenced journals. His research interests include the performance, pathology, in situ testing, diagnosis, maintenance, rehabilitation and service life prediction of buildings and construction elements and sustainable construction.

Bárbara AMARO. Holds a Master's degree in Civil Engineering from Instituto Superior Técnico, Technical University of Lisbon, Portugal. Her research interests include the life cycle of construction elements. 